\title{
Online Adjunct Faculty Perceptions of Professional Development to Support Personal and Professional Academic Growth During COVID-19
}

Cheryl Burleigh, EdD

University of Phoenix, Phoenix, Arizona, United States

(iD https://orcid.org/oooo-0003-2393-5477

Patricia B. Steele, EdD

University of Phoenix, Phoenix, Arizona, United States

(iD) https://orcid.org/oooo-0oo1-6533-4990

Grace Gwitira, DM

University of Phoenix, Phoenix, Arizona, United States

(iD) https://orcid.org/oooo-0002-5026-2549

Contact: drcburleigh@gmail.com

\section{Abstract}

Objective: The purpose of this study was to understand what online adjunct faculty value as support services, specifically professional development opportunities, provided by their respective higher education institutions.

Method: This qualitative narrative inquiry study centered on exploring perceptions and experiences of online adjunct faculty members from higher education institutions and their experiences and expectations of professional development (PD), prior to and during COVID-19.

Results: The study resulted in the identification of possible improvements and enhancements to existing PD content that would further support faculty personal development, mental health, wellbeing, and academic growth.

Conclusions: This study reminds us that there are numerous variables, including unforeseen crises such as the COVID-19 pandemic, that need to be considered when developing, implementing, and presenting PD for online adjunct faculty professional and personal growth. Because faculty want to be listened to and heard, the PD development and implementation process needs to be interactive to support online adjunct faculty, regardless of whether the university is for-profit or not-for-profit.

Implication for Practice: The results based on online adjunct faculty experiences could lead to updating professional development opportunities employed in different higher education institutions to promote faculty self-actualization and ultimately, student success. 
Keywords: professional development, online adjunct faculty, COVID-19, higher education, for-profit universities, notfor-profit universities

Submitted: March 6, 2021 | Accepted: July 24, 2021 | Published: October 25, 2021

\section{Recommended Citation}

Burleigh, C., Steele, P. B., \& Gwitira, G. (2021). Online adjunct faculty perceptions of professional development to support personal and professional academic growth during COVID-19. Higher Learning Research Communications, 11(2) 68-91. DOI: 10.18870/hlrc.v11i2.1241

\section{Introduction}

Due to the current climate of the COVID-19 pandemic, significant value exists in investing in university and faculty development, especially when one of the main aims is to strengthen the mental health and wellbeing of faculty members (Baker, 2020). Online colleges and universities take various approaches to program design, technology delivery models, structural development, and quality of professional development (PD) programs. The lack of uniformity in approach means that across and within higher education institutions, various college or department driven strategies are applied to the development of PD programs that create inconsistencies that may not be helpful to fulfilling the mission and vision statements of the respective college or university.

An effective uniform PD delivery framework could be used by colleges and universities to help them deliver consistent online PD for adjunct faculty (Diep et al., 2019; Guskey, 2003). Guskey (2003) posited a need to formulate PD programs that are effective with clear descriptions to support faculty. This is especially true in the era of COVID-19 where online adjunct faculty rely on their institutions' programs and services to help provide essential PD to support faculty mental health and well-being while actively engaging students in meaningful learning experiences.

\section{Literature Review}

The COVID-19 pandemic has greatly impacted tertiary education systems globally and challenged stakeholders; therefore, supporting online adjunct faculty through updated professional development could assist in creating a more positive distance learning culture during this time (Almazova et al., 2020; Gutterman \& Mitchell, 2016). Piazza and Rizzari (2020) affirmed the importance of improving the quality of university teaching. However, while the correlation between the PD of faculty and the improvement of student learning is apparent, PD has not been given continuous and systematic attention (Penuel \& Gallagher, 2017).

When online adjunct faculty participate in PD opportunities, an expected outcome is to actively engage with other faculty and the PD content presented to develop and acquire skills that can be translated to actual application in the classroom to support student learning. Online adjunct faculty see the importance of PD offered by their institution as a means toward collaborative and collegial relationships leading to enhanced teaching, thus fulfilling a possible void in professional skills (Gast et al., 2017; MacPhail et al., 2019; Stewart, 2014). A desired result of the PD process, either in workshops or training courses, is to include opportunities for active learning where there is a greater probability of building awareness about and focus on curriculum content for faculty to authentically learn tasks based on real-world activities (Doherty, 2011; Gast et al., 2017; Gutterman \& Mitchell, 2016; Stewart, 2014). Institutions of higher education develop PD for their faculty in the hope that the intended learning outcomes of the training course will be employed in the classroom (Doherty, 2011). In most cases, faculty do not implement the practices or skills presented during their PD in the classroom, even when the professional development workshop or course received favorable ratings for the experience and information learned (Doherty, 2011).

The expected outcomes of PD offered by the university, college, or department are that the concepts and standards delivered are intentionally practiced by faculty when engaging with students in the classroom 
(Kuder Coach, 2018). Thus, the university needs to design and develop authentic PD activities and learning environments to support faculty that include collaboration and reflection, and where needed, coaching to continuously reinforce the teaching values of the institution (Herrington \& Oliver, 2000; Stewart, 2014). When online adjunct faculty are not able to actively translate the skills and practices learned into changed teaching behavior, a disconnect occurs. Therefore, the possible outcomes for both the university and faculty of implementing meaningful PD opportunities may be thwarted by barriers such as department support for innovative practices, politics within the institution, motivation, or a cultural disconnect with online adjunct faculty based on shared values and norms (Dede, 2004; Diep et al., 2019; Gast et al., 2017; Rienties et al., 2013). When attitudes, motivation, commitment, self-efficacy, professional identity, and availability of online adjunct faculty are considered, there is a greater probability for successful implementation of PD by higher education institutions (Gast et al., 2017; Hwang, 2021).

Various successful avenues for quality PD in higher learning for online adjunct faculty exist. For example, planning and providing ongoing PD experiences for online adjunct faculty at different stages of their tenure within a department or college could aid in encouraging successful implementation of university-based pedagogy (Felber, 2020; Frass et al., 2017; Hwang, 2021). Ongoing PD evaluation also could result in facultycentered, ongoing professional learning opportunities moving toward quality PD faculty support (DarlingHammond et al., 2017).

Faculty will pursue PD if the content is equitable, meaningful, includes praxis and reflection, and will increase their level of job satisfaction throughout their career (MacPhail et al., 2019; Stewart, 2014). Most faculty will seek PD to stay fresh in their respective field of content knowledge, develop new strategies to improve the delivery of course content, and to meet the needs of their students to increase classroom engagement (Queens University of Charlotte, 2021; van Dijk et al., 2020). If faculty are not presented with meaningful PD from their institutions, professional organizations and conferences may offer information related to PD, since professional organizations have the capacity and flexibility to provide online webinars, workshops, or conferences that address current issues faced by higher education faculty (Salmi, 2020).

To improve expectations of professional learning, colleges and universities have various methods of delivering PD training to their online adjunct faculty. Several studies exist that suggest how to evaluate the effectiveness of PD offerings (e.g., see Baran \& Correia, 2014; Dailey-Hebert et al., 2014; Mohr \& Shelton, 2017). However, a gap in the literature was found on a strategy or framework for understanding the desired outcomes of faculty for their PD experience. Mohr and Shelton (2017) maintained that while the aim of university-based PD was to develop faculty best practices for professional growth and further student learning, a need still exists to support online adjunct faculty through a collegial campus climate that goes beyond the "typical focus on technology, pedagogy, and course content" (p.134). Within the realm of PD, many higher education institutions do not recognize the shifts in the knowledge base, motivation, and commitment of online faculty or the timing in which PD events should occur (Dailey-Hebert et al., 2014; Diep et al., 2019). Higher education institutions are struggling to navigate the unprecedented demands to support their faculty during 'normal' times, yet the chasms have been exacerbated due to the global pandemic (Roy \& Covelli, 2020; Ulmer, 2020; Vlachopoulos, 2020). Acknowledging that a direct correlation exists between the quality of teaching and the effectiveness of online programs offered by universities (Baran \& Correia, 2014) may help drive the need for universities to further invest in meaningful professional learning opportunities for faculty. Therefore, understanding the needs of online adjunct faculty and rethinking goals of PD through thoughtful planning can increase faculty engagement, effectiveness in the classroom, and loyalty to their respective institution (James \& Binder, 2012; Williams et al., 2014).

To support online adjunct faculty in obtaining PD training opportunities, dependence on reliable mobile technologies has increased even more so with the advent of classes moving from traditional face-to-face classroom interactions with students to online platforms (Earp, 2020; Vlachopoulos, 2020). Setswe et al. 
(2019) affirmed that the use of mobile technologies for PD in higher education has not been investigated and is overlooked. Mobile technologies in the context of this study refer to the use of tablets, laptops, and cell phones as means for institutions of higher education to communicate and offer PD to their online adjunct faculty. Moreover, university human resource departments seldom, if ever, have set policies or frameworks addressing training and support for online adjunct faculty (Schaffhauser, 2015; Straumsheim, 2015).

The purpose of this research was to analyze the effectiveness of PD programs in higher education institutions in the United States, along with clear descriptions of contextual factors that may affect quality PD programs in higher education. Employee development is important in developing good and reliable workers and will enable them to improve their performance (Asio \& Jimenez, 2020). Therefore, it is critical to provide continuous training to online adjunct faculty to improve student attainment of learning outcomes and engagement in the classrooms.

\section{Theoretical Framework}

In the current study, the integration of Knowles' andragogy theory, Maslow's hierarchy of needs theory, and the studio thinking framework and habits of mind served to establish the foundation of the relationship between online adjunct faculty's need for professional growth, self-actualization, and implementation of skills learned to further their professional craft. Each of the theories are intertwined in their application to online adjunct faculty in the context of professional development and pursuit of career satisfaction. A direct reference can be made between each of the theories and the processes needed to continuously support online adjunct faculty learning with a connection to their respective institutions of higher education.

\section{Knowles Andragogy}

Andragogy is the "art and science of helping adults learn" (Knowles, 1980, p. 43; Loeng, 2018, p. 4). Knowles affirmed that adults are "self-directed, problem-solving learners whose life experience constituted a significant learning resource" (Bartle, 2008. p. 1). Adults are keen to discover knowledge to which they can attach more meaning and have the potential to grow within their professional and personal practice (Namaganda, 2020). Andragogy theory stands on the premise that adults develop intellectually, emotionally, and psychologically, in accordance with their age. Online adjunct faculty thus have distinct needs for their development (Bartle, 2008).

Knowles developed specific assumptions of andragogy. The first assumption is that adult learners, and for the purpose of this study, online adjunct faculty, have an autonomous perception of self and can self-direct their own learning. The second is that adults accumulate a wealth of life experiences that serve as a foundation and a resource for their own learning. The third assumption is that adults are motivated to learn by their sense of what is needed for their growth and roles in society. Assumption four describes the adult learner as centered around and interested in applying knowledge immediately. The last assumption is that adults are driven to learn by internal factors and not by external factors (Bartle, 2008; Loeng, 2018; Merriam, 2001). Accordingly, humanistic psychology views Knowles' theory of andragogy as a process where each learner is "autonomous, free, and growth oriented" (Merriam, 2001, p.7).

Andragogy has increased with the popularity in distance learning (Shilpa Joshi, 2017). Students who were resolute and autonomous perceived taking classes and open university courses online as the ideal means for learning and completing a degree program that fits their lifestyle (Hussain, 2013; Shipla Joshi, 2017). Thus, andragogy is viewed as learner-centered and specifically applicable to non-traditional adult learners (Shilpa Joshi, 2017). In this study, the perceptions, and expectations of adjunct faculty from online non-traditional institutions of higher learning is being sought. The discussion of andragogy in the current research demonstrates its usefulness for exploring some of the frameworks and issues associated with professional 
development for online adjunct faculty; this is essentially a function of adult education. Andragogy also contributes to how we understand the experiences and perspectives of online adjunct faculty as adult learners.

Hussain (2013) concluded that remote learners had a high level of satisfaction. If the learner's selfactualization is the goal of andragogy (Knowles, 1980), then the facilitator's role is not unlike that of a coach who creates an environment and provides resources to help the adults realize their full potential and move toward fully independent learning. Since the population for this study is from adjunct faculty teaching online, these faculty qualify as remote learners in the context of growing in their professions.

\section{Maslow's Hierarchy of Needs}

Maslow's (1943) hierarchy of needs theory includes five levels of human needs with the highest being selfactualization. As shown in Figure 1, Maslow's hierarchy of needs consists of (1) physiological, (2) safety, (3) love and belonging, (4) esteem, and (5) self-actualization. As we move from a lower level to a higher level of the pyramid, the need becomes less complex, and the number of people who realize that need decreases (Schulte, 2018).

Figure 1. Maslow's Hierarchy of Needs

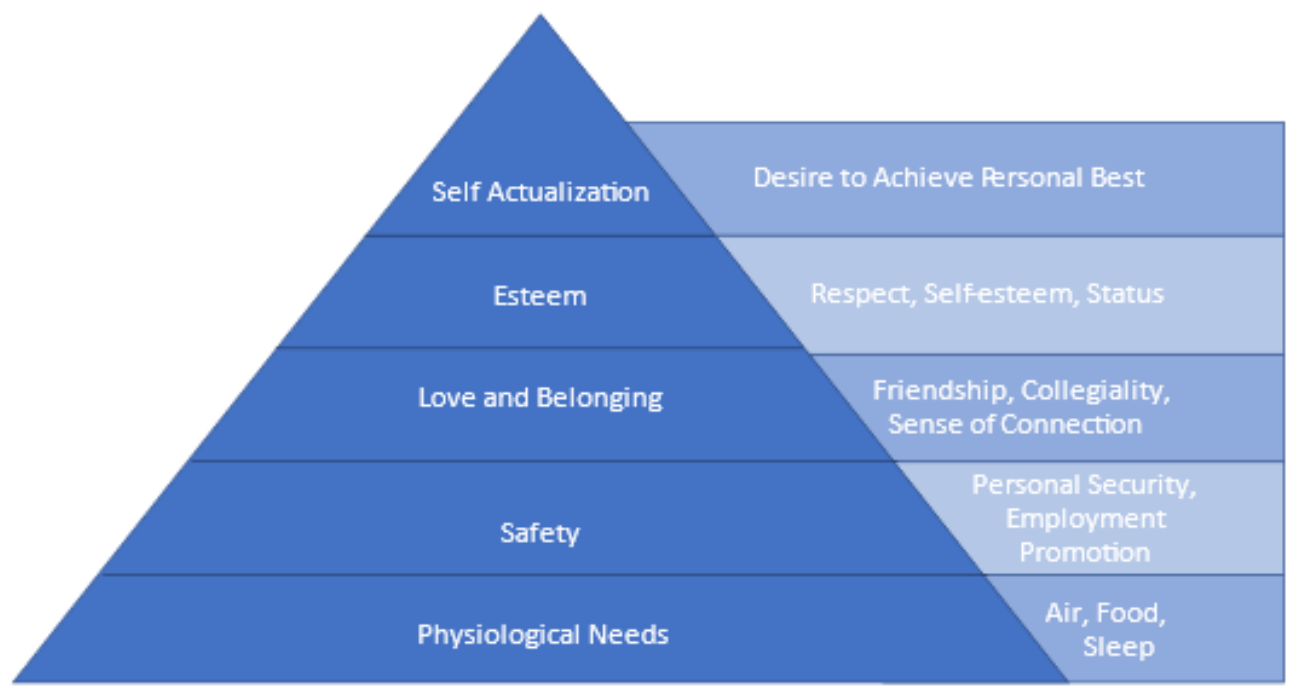

Note: This model is adapted from the traditional Maslow's (1943) hierarchy of needs to support the needs and selfactualization of online adjunct faculty.

Maslow's (1943) theory can be used in the context of professional development for online adjunct faculty. Most online adjunct faculty have already had their physiological needs of air, food, and sleep met because they already work at non-traditional universities to earn money or resources for food and recognize the need to sleep to carry out their duties (Schulte, 2018).

The next level of Maslow's (1943) theory is safety. Safety for online adjunct faculty may mean having a job but being uncertain about its permanence, especially given the challenges on the economy presented by the current COVID-19 pandemic. The fact that these adjunct faculty work online means that they do not have the safety concern of contracting the COVID-19 virus through in-person interaction with students and other 
faculty. Their concern regarding safety may be tied to having a secure job or a promotion, which may be linked to skills advancement and career development.

After safety needs, the next level of love and belonging may relate to job security but with a desire to increase one's income, work with various people, and increasingly enjoy the work. As online adjunct faculty's pay and quality of life increase, they may perceive a career development program as a means to increase pay. As income and quality of life improve, they may view additional education as a way to make more money, have more family time, save more money for retirement, and develop their personal interests.

The fourth level of esteem may translate to a desire to obtain a terminal degree for the title or to impress other people. At the highest stage of Maslow's (1943) theory, online adjunct faculty have attained stability in their career but are driven to go further, driven by both extrinsic and intrinsic motivation, which may comprise leadership roles and executive positions. Adjunct online faculty members may strive to improve work for others by actions such as conducting empirical research.

During level five, self-actualization, experienced online adjunct faculty may include "lifelong learning, desire to mentor others, pursue a retirement career, or engage in philanthropy" (Schulte, 2018, p.64) to further develop their personal growth. Because many find self-actualization difficult to attain, online adjunct faculty who desire to achieve their individual best professionally may have difficulty reaching their goals (Schulte, 2018). Understanding the needs of online adjunct faculty can pave a way to improve existing or newly developed PD programs (Schulte, 2018). Personal growth, either in one's private endeavors or professionally, is the essence of self-actualization which in turn increases self-esteem and career satisfaction (Abela, 2009; Easterly \& Myers, 2019).

\section{Studio Thinking Framework and Habits of Mind}

The studio thinking framework (STF) was initially developed following observation of art classes and is thus usually associated with visual arts courses. STF can also be applied to professional development for online adjunct faculty. Relationships between the seven interconnected components of the STF can be drawn to explain how adults in the virtual environment can learn and develop creative and cognitive skills (Hetland et al., 2013). Seven different habits of mind (HoM) or dispositions are illustrated in Figure 2. These dispositions, identified by Sheridan (2009), include observe, envision, engage and persist, express, reflect, stretch, and explore, and perfect a craft. The emphasis of HoM reveals a perspective that the goal of education is not predominantly just work but to "take an engaged, attentive, creative, thoughtful, and skilled approach to work and working" (Sheridan, 2009, p. 73) and that the dispositions ought to be utilized in all areas of learning. 


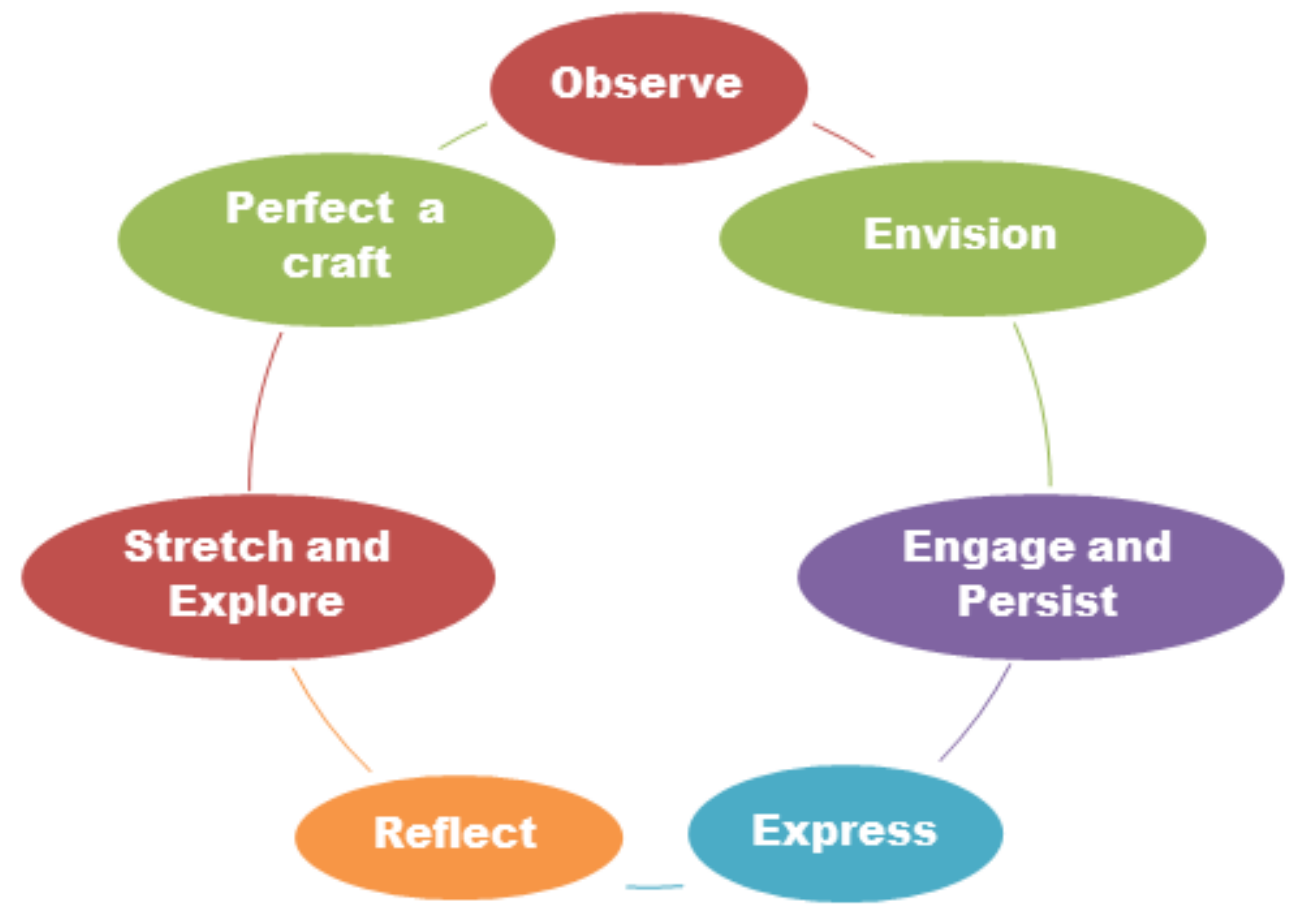

Note: The adapted model, developed by the authors of this study, shows the circular and continuous relationship between each of the seven dispositions within the Habits of Mind (Sheridan, 2009) beginning with the disposition of "observe," based on the Studio Thinking Framework as initially proposed by Hetland et al. (2013).

Perfecting a craft involves learning the appropriate language and conventions relevant for the instruction, as well as learning the tools required for internet-based education (Frerichs et al., 2018). Engagement and persistence apply to learning to accept associated problems inherent in the professional development program that are significant to the online adjunct faculty member's learning. Engaging and persisting also involve being focused and adopting the mental fortitude favorable to working and persisting with each learning activity (Sheridan, 2009; Steele et al., 2020).

Envisioning implies that the online adjunct faculty have a vision of where they want to go in self-development and career advancement. Based on Maslow's hierarchy of needs, people thrive to fulfill their higher order needs and thus one can surmise that the online adjunct faculty member is in pursuit of or envisioning themselves in a better position because of the professional development program. Envisioning one's path toward personal academic growth is an intrinsic disposition (Hetland et al., 2013). Demonstrating and expressing personal meaning or feelings could relate to the thinking that adults attach meaning to their learning, which is tied into their societal roles. Observing learning is a component of the framework that calls for critical analysis of the material being learned as to see beyond the ordinary.

In applying aspects of the STF framework, adjunct faculty members' online collaboration could inspire understanding through threaded discussions and video conferences. Online adjunct faculty members can evaluate their own work and growth against given standards of proficiency from their respective university, college, and department (Namaganda, 2020; Tyers \& Sillito, 2018). To stretch and explore, online adjunct faculty must challenge themselves with an open mind and be willing to learn from unintended outcomes (Steele et al., 2020). At the heart of one embarking on a professional development program is the goal of 
understanding the material and being able to apply the skills learned to further career advancement, job satisfaction, and relevance to teaching practices within the field of higher education (Sheridan, 2009).

In the visual arts, just as in the art of teaching, the seven STF processes could build toward a perfect, envisioned result or craft by online adjunct faculty to master content to support student learning. Within higher education, when developing effective and meaningful PD opportunities, the process could engage and encourage online adjunct faculty and students to interact, working toward a common, acceptable goal within the instructional process. Thus, both the student and online adjunct faculty members could be able to envision a path towards academic and professional growth.

\section{Purpose of the Study, Research Questions, and Rationale}

The purpose of this qualitative study was to obtain online adjunct faculty members' expectations, experiences, and perceptions of the PD support offered at their respective online institutions. The following questions guided this study: What are the expectations of online adjunct university faculty when PD is delivered in an online format? and What are the experiences of online adjunct university faculty when PD is delivered in an online format?

Implementing a qualitative narrative inquiry approach, findings from the present study were compared with PD experiences from online universities, possibly introducing standards that could be used in other institutions (Guskey, 2003; Tyers \& Sillito, 2018). Results could benefit online university PD programs and provide mechanisms for their continuation despite crises such as the current need for social distancing necessitated by the COVID-19 pandemic. Universities offering online PD programs are not location specific and can offer the programs at a convenient time (Setswe et al., 2019; Vlachopoulos, 2020) to support online adjunct faculty who are adjusting to teaching students who are more vulnerable and stressed due to the COVID-19 pandemic.

Implementing effective PD programs, which are current and relevant, could lead to increased faculty career satisfaction leading to increased student success (Curwood, 2011; Darling-Hammond et al., 2017; Showers et al., 1987). Easterly and Myers (2019) posited that seeking esteem and self-actualization is revealed through career satisfaction. Maslow's (1943) theory of motivation presents self-esteem and self-actualization as the highest motivators in the hierarchy of needs.

Although each of the online adjunct faculty study participants were skilled in their respective fields, understanding specifically what online adjunct faculty expect in PD opportunities is critical to promoting their professional growth and engagement. When higher education institutions are active partners in PD, online adjunct faculty may feel a deeper level of appreciation from their respective universities and departments (Cheatham, 2020; Roy \& Covelli, 2020; Vlachopoulos, 2020).

\section{Methods}

\section{Nature of the Study}

A qualitative narrative inquiry approach was employed for this study to obtain a deeper understanding and gain the insights and perspectives of online adjunct faculty's experiences of PD at their respective institutions. The use of this approach allowed the participants latitude to express their views, feelings, beliefs, and perceptions regarding personal experiences with PD at their respective institutions through semi-structured interviews (Kim, 2016; Riessman \& Speedy, 2018). Additionally, relevant, valuable, and insightful research data can be gleaned during a narrative inquiry regardless of the number of participants (Boddy, 2016). Through a content analysis, the stories of the study participants demonstrated how their PD experiences 
shaped their perceptions as contributing online adjunct faculty members of their teaching practices and their universities.

\section{Population and Sample}

The study, approved by IRB, included a population of experienced adjunct faculty from online universities who, at the time of this study, were members of the Association for Educational Communications and Technology (AECT), which is an educational professional organization. An invitation was sent to approximately 2000 members located inside and outside of the United States. Study participants were online adjunct faculty in higher education who had a minimum of five years of online teaching experience for a university or college and who had experienced and completed any of the required and optional PD programs, training, or frameworks during their employment at their respective institution. Those expressing interest in participating in telephone interviews were sent an invitation letter providing details of the study as well as an informed consent to be signed and returned to the researcher. From the initial 40 potential study participants who responded to the research invitation, 18 committed to be interviewed. Participants for the study included associate, part-time, or full-time adjunct online faculty from not-for-profit (NP, N = 10) and for-profit (FP, $\mathrm{N}$ $=8$ ) universities from 12 different higher education institutions. Pseudonyms were assigned to each of the participants. Those individuals who did not commit to the interview may not have met the study's requirements, were disqualified based on the outlined criteria, or they self-selected not to proceed to the interview phase of the study. The prescribed qualifications allowed the researchers to capture the participants' insights and experiences regarding the types of PD and support received by faculty who work for online higher education institutions.

\section{Instrumentation}

The nature of the open-ended questions (see Appendix) provided a platform for each participant to spontaneously answer questions and expand upon responses to paint a clear picture of required or optional university-based PD availability. There were five categories of questions asked of participants during the interviews which included: types of PD experiences offered by their university or college, how adjunct faculty were able to provide feedback to their institutions during PD, personal academic growth opportunities during $\mathrm{PD}$, experiences with their specific institution in relation to PD, and the PD experience when they had onboarded for their current adjunct faculty position. The process of a semi-structured interview allowed for a free flow of dialogue in a conversation style where the participants felt at ease to share their perspectives about how PD at their institution is developed and rolled-out to online adjunct faculty; the frequency, intended purpose of each meeting, session, or workshop; and if online adjunct faculty are encouraged to seek additional PD offerings at their respective university or elsewhere.

\section{Data Collection and Analysis}

Interviews were conducted to gain a deeper understanding of experiences of PD and how PD opportunities contributed to their personal academic growth. Telephone interviews were digitally audio recorded and transcribed by the person conducting the interviews. The same researcher transcribed the audio recordings and sent the Microsoft Word document to each participant for member checking (Yin, 2018).

During the initial phase of analysis, demographics were identified, and pseudonyms assigned. To accompany each pseudonym, the abbreviation of not-for-profit (NP) or for-profit (FP) was included to delineate the type of higher education institution of the study participant. The inductive analysis process was employed where a comprehensive understanding of the data was expounded, including units of meaning and findings (Buus \& Perron, 2020; Ziegler et al., 2006). To visually denote each of the themes and establish codes, the text was highlighted in five different colors in a working Google document (Johnston et al., 2017; Saldaña, 2015: Saldaña \& Omasta, 2022). This assisted in the identification of reoccurring themes. Team members 
individually analyzed each of the participants' transcripts. The team collectively reviewed the results of the participant's accounts several times, identifying emerging codes, noting categories, followed by highlighting specific themes. Several categories which constituted the themes emerged from the content analysis of the participant's transcripts. The specific themes were centered on the six categories identified as Communication and Collegiality; Importance of Professional Development Content; Synchronous Engagement; Faculty Needs to Support Students; Relevance of Professional Development Content; and Self-actualization.

\section{Results}

Participants met the minimum of five years of online teaching experience with an average of 12 years teaching in an online learning environment. There were 10 female and 8 male participants whose ages ranged between 30 and 78. A substantial online presence, for the basis of this study, is defined as $80 \%$ or more of the student population taking all of their courses online (Lederman, 2019). Each of the participants were active online adjunct faculty during the COVID-19 pandemic and shared personal perspectives based on their understanding of the PD frameworks of their respective higher education institutions. Since the study had taken place during the summer of the year 2020 when COVID-19 was rampant, participants were able to discuss PD experiences prior to the onset of the global pandemic and how COVID-19 may have placed an emphasis on the need for PD, including its importance, frequency, and mode of delivery, and the impact on their teaching and student concerns. Presented below are the results from each of the following themes: Communication and Collegiality; Importance of Professional Development Content; Synchronous Engagement; Faculty Needs to Support Students; Relevance of Professional Development Content; and Selfactualization.

\section{Communication and Collegiality}

When online adjunct faculty were asked about their top concerns regarding PD offered by their higher education institutions, effective and meaningful communication and collegiality were the most discussed topics. The participants reported that communication between universities and their online adjunct faculty is critical, especially during COVID-19, for understanding exactly what type of PD may need to be developed and offered to meet online adjunct faculty needs for personal and professional academic growth. When higher education institutions treat online adjunct faculty with collegiality and listen to their voices, faculty feel that they are heard, respected, and valued. Below are some of the responses indicating the importance of communication and collegiality.

You mean you want to hear what I want? That's great because at least I know someone is listening. First, as an online adjunct faculty member I would like to be heard. Faculty have great ideas and suggestions to support meaningful PD for all faculty that are motivated to support students in their dreams of earning a higher education and degree. Faculty need to have a voice, and that there are faculty who are in the trenches daily with our students, who have a voice that matters. Katy (FP)

The main concern with PD, which I think my University does a great job of, is to listen to what online adjunct faculty need and want, especially since COVID has struck. Those issues include flexibility in how we should work with students who may be affected by COVID, grace periods for assignments or the modification of the depth or number of assignments per week. This shows faculty that the University really cares about us and values the contributions that we make in delivering course content and supporting student success. The other thing, that what is presented during the PD is appropriate for right now, are current, and we can immediately apply in our classes with our students. Also, faculty have the chance to network and engage with other faculty, which we really need. This is important so that we know we are not alone as online adjunct faculty, you sometimes feel that way. Delia (NP) 
With any PD, the topics need to be current. We don't want tried and true rehashing of the old PD. That just turns off faculty. Instead online adjunct faculty need to be polled and solicited often by the school and university as to what are the concerns or issues that are affecting students and faculty now, today. Those are the PD events that need to be developed quickly and rolled out within four to six weeks. What I can say, both the school and the university seem to understand the urgency of relevant, timely, and current PD which is more important now because of the pandemic. By the university listening to faculty input, then you have faculty who will be true to the school and university and will remain with the institution for the long-haul. When faculty are recognized as professionals and the valuable insights they bring to the table, the school, and the university benefits. The school and the university should think of themselves as a living, breathing entity. Therefore, the process is ever changing and organic. Carly (NP)

I will say, when I first started teaching for the University, there was a real positive attitude about online adjunct faculty, we were valued and our voices were heard. We were regularly contacted for our opinions on what we wanted to see in PD, updates to curriculum, and any other concerns that we had. This wasn't because I was new or this was a honeymoon period. Other faculty that I was able to network with felt the same and they had been with the University longer. Now, we feel overworked and underappreciated, even more so with COVID. I have had to take on additional students, many of whom normally were taking classes in-person at a local campus and this is their first time in distance learning. Why would I give my time to a PD that will not be a value-add to my teaching and students? Sara (FP)

\section{Importance of Professional Development Content}

The following excerpts from the participant interviews demonstrated that online adjunct faculty have an ongoing awareness of the importance of PD content. Depending on the university and the value placed on online adjunct faculty PD, the participant's experiences varied greatly. Faculty observed if their departments and universities were open-minded and informed, and whether the content presented in PD was more likely to be relevant and current. Faculty were able to be informed and take an active role in the PD process.

The content needs to be up to date and the way it is delivered also differs from one training to the next. It looks the same and in some cases the questions are the same from one training to the next. How do I know? I keep a copy of the questions and my responses from the previous training. $\sim \operatorname{Bernie}(\mathrm{FP})$

The content of the PD events must be those in which online adjunct faculty can directly relate to, is new, and current. Right now we need PD that addresses issues surrounding COVID. Issues from COVID for faculty is the impact on non-online students now having to integrate into distance learning. Some of those students are floundering. We need to know how to work with these students. Much of the PD from the training seems to be the same, slightly updated but overall, it's nothing to write home about. We need current and updated content that addresses real issues that faculty are experiencing now, like COVID, in the class with students, like mentioned above. Have faculty facilitate PD. Our faculty are very talented and should be able to take on these roles, not just lead faculty or program managers, real boots on the ground faculty. This is how the university can gain credibility with its faculty. Katy (FP)

The content is well developed by the PD developers, program managers, and administrators. Everything is well thought out for the specific training, workshop, and webinars offered. Each of the events have current information that directly applies to support our students and is led by faculty, who we can relate to. Allowing online adjunct faculty to take an active role in PD brings credibility to each of the events offered. Lisa (NP) 


\section{Synchronous Engagement}

When asked about expectations of PD opportunities provided by their universities, the online adjunct faculty study participants stated engagement was of great importance, especially when engagement is synchronous. Faculty acknowledged that while asynchronous meetings have value for policy based or mandated training, there is a strong preference to meet with colleagues in real time for meaningful interaction and immediate feedback. Based on the study participants' responses, adjunct faculty who taught at institutions that placed importance on synchronous professional development were more satisfied in teaching at their respective institutions. Responses highlighting engagement included those below:

In a PD event, I want and expect to be engaged in the event. Engagement means there is interaction with participants and between participants, in real-time, not just asynchronously. I want and expect to learn information that is timely which I can then use immediately in the classroom or professionally, such as how to support my students during COVID. I want and expect that to be respected and have the ability to share opinions, ask questions, and obtain answers live during such events. $\sim$ Steve (FP)

The PD for my for-profit university is old and tired looking and there is no real faculty interaction. A few of the online adjunct faculty who may know each other will respond to one another in the discussion posts. And the facilitator tries, but they are overwhelmed by the sheer number of people in the workshop. To be active or want to be active in $P D$, there needs to be real-time engagement with faculty. The topics to be presented need to be current and relevant to faculty and translatable to the classroom. Also, I need to learn something that I didn't know before, maybe a new skill or technique or how to integrate technology into my classes. $\sim$ Bernie (FP)

Faculty need opportunities to engage with other faculty, to interact in a live setting. That's how we share best practices and learn from one another. Asynchronous training is great for HR type of compliance, but for day-to-day type trainings, live is the way to go. Now if people cannot go to a live session, then record the session so others can listen later on. If they have questions or something to add, then they can correspond with a specific person. $\sim$ Katy (FP)

I understand having an asynchronous system for general online adjunct faculty meetings and the content area meetings, but these are not beneficial. I feel that I am only going through the motions to check off a box for compliance. There is no true interaction. Even though I feel these types of meetings are a waste of time, I do them anyway so that I can still work with my students. $\sim$ Bree $(F P)$

When I do attend an event, first I expect that the PD is well run. The smoother the better, that makes the event enjoyable. Then I want to be sure when I go to the event, I want to be able to engage with others while learning something. If I am taking time out of my day, not getting paid, then it better be an event with content that will help me be a better faculty to my students. Jason (FP)

To have a positive experience in PD first would be to listen to what faculty really would like to have as a professional growth opportunity. To have a positive PD experience the content has to be engaging and it has to be relevant. Additionally a great PD is succinct and to the point. Faculty, just like everybody else, have time constraints and currently are going through Zoom burnout because they are on video conferencing continuously. $\sim$ Ray (FP) 


\section{Faculty Needs to Support Students}

The following excerpts from the participant interviews demonstrated that online adjunct faculty have an ongoing awareness and knowledge of their roles as faculty members representing their universities, a conduit of teaching knowledge based on the mission and vision of their institutions, and supporting student learning and degree completion.

The university needs to invest in developing new PD content. The only way this is going to happen is if the university listens to faculty and we have a voice. Consensus among FP Study Participants

For PD to have meaning to me, not only do I need to learn something, a skill, or a new program, but I need to have content that is applicable today, that I can use right away or have access the minute I need it. In live trainings or webinars, the content does need to have a sense of urgency, more so with the global pandemic and how this affects us and our students. Katy (FP)

If I were to design a PD, I would make sure there are opportunities to engage. I would make sure what is shared in PD sessions, webinars, and trainings are relevant and of interest to faculty. Right now, concerns surround the global pandemic, and those discussions are needed. Most importantly, ask faculty what they would like to see. What are the things or skills they need in order to best serve students? Missy (NP)

Most important is that the information that is presented in a PD is current, what is happening in the world, and directly related to the content and what our faculty and students need. Also, that faculty and leads who are supporting us listen to our feedback and then incorporate that feedback into the upcoming PD. Also, that the PD is sustained over time and that there is always engagement with faculty. What I like is that our opinions are requested and that we are really being listened to. Anita (NP)

The PD I need to see is based on supporting students who are feeling isolation, having difficult times, and are stressed based on COVID. I need strategies from the University and resources I can share to support these students. Same with Black Lives Matter. For some of our students they have been impacted by both events. The University needs to show that they care and provide faculty the resources needed to support our students. Again, this comes down to recognizing the problems currently happening in the world and then develop PD that is timely to deal with such occurrences. Olive (FP)

When attending any PD, my hope is that I will be learning a new skill, best practice, or something that is relevant to my students or my needs. An example would be learning a form of mediation practice that can help to reduce stress, especially now because of COVID. I want to be able to interact with other faculty and actively engage in learning. Carly (NP)

To support my personal growth, I would like to see specific PD opportunities and strategies of how to support students who are going through isolation or feelings of isolation, difficult times, have extenuating circumstances, and overall feel stressed. If such PD is available with specific current strategies, then I feel I would be in a better position to be able to point my students in the right direction to get additional support. I would also be able to have basic strategies and means of being able to encourage my students even though they feel the weight of the world on their shoulders. I am not a psychologist or psychiatrist so I do not have these strategies or tools available to me to support my students. This is where the University needs to step up to support faculty and their growth as facilitators in the classroom. Ted (FP) 
Most of the training is to keep us up to date in how to teach our students. The recent workshops included a topic that was current and relevant, Innovations in Remote and Blended Classrooms. One of the questions that drove the workshop was: How do we get that knowledge and that love of our topic area to our students, who will continue to grow with it in their own assignments and readings? The workshop looked at how to integrate technologies to further engagement of students in the class, even using Kahoot in this capacity and looking at other video conferencing features. $\sim \operatorname{Ajay}(N P)$

\section{Relevance of Professional Development Content}

When discussing the relevance of professional development content, online adjunct faculty from both not-forprofit and for-profit universities commented on the direct connections of PD to curriculum and the immediacy of what is needed in the classroom. The following excepts are indicative of those conversations:

Really it has to do with the information having to be just in time, relevant, and something that I can relate to, which will allow me to improve my teaching to assist students. We need this type of support, really right now [due to COVID] in how to know how to handle delicate situations that may have been brought on by the global pandemic. Bernie (FP)

Having guest speakers at PDs provides a different perspective as to what is available at the university and how to access that information. Plus, we can ask all types of questions. The speakers share specific resources that are available to faculty this includes assistive technology and resources to support faculty and students. Gretchen (NP)

If you have a PD experience that is interactive and engaging, people will come and they will walk away learning something. I just attended PD within my department where we are meeting once a week for four weeks to discuss specific topics related to teaching in higher ed and COVID. Ray (FP)

I would like to see PD developed based on faculty concerns and that is current and relevant. Such as how do we work with students who are experiencing COVID or the hardships that have occurred because of COVID. How about webinars to support faculty mental health and wellness. Or what about developing a webinar group that gets together to do yoga together. Sam (FP)

\section{Self-Actualization}

Participants were cognizant of the role they play in PD events offered by their respective higher education institutions. There was agreement among participants that online adjunct faculty are responsible for getting the most out of PD experiences offered, coming into each meeting with an open mind and a willingness to learn something new that may benefit themselves and their students. Self-actualization was perceived by the participants as their level of satisfaction with PD opportunities to support their personal and professional academic growth; being free to have the creativity to reach their learning potential; and successfully apply what had been erudite, which can then be applied to their teaching practice. To fully understand selfactualization, online adjunct faculty recognized personal strengths to build on and understand challenges faced regardless of world events. Having the fortitude to recognize the characteristics of self-actualization in the context of the COVID-19 pandemic can bring about a recognition of core personal values. In particular, the well-being of faculty was imperative to successful teaching and integration of meaningful and relevant curriculum when supporting students during unprecedented times. Self-actualization is reflection in the quotes below:

Each PD I have gone to I have learned something. The skills and strategies learned from other faculty have made me rethink how to teach classes, get students engaged, and really listen to what 
my students need now. Also, I learn new strategies of how to deal with different and difficult issues that are happening right now that our students face and how I can better help them cope. Ashlee $(N P)$

I have enjoyed each of the PD experiences that I have been involved in. I always end a PD event excited that I met someone new, learned something new, and was able to share experiences with program managers that have the ear of the college, so my voice is heard. I do feel that my voice is heard, which makes me feel good. Delia (NP)

I like the variety of training, especially now with a focus on students and how they are doing in the midst of COVID. Continue the focus on faculty and student mental health. I also like the blogs on PD. The University is not afraid to direct us to other places that have great PD available, especially during this crisis. Ajay (NP)

I go into every PD knowing I will be able to network with other faculty and be immersed in an event where I will learn something new that I can use in the classroom with my students, in my personal research, or to better myself as an individual. My expectations are not to be entertained, but to get resources that can help me help my students. I do love the ability to engage with other faculty. It's always fun to see what others are up to, hear stories, and learn best practices. Anita (NP)

It's an opportunity to get together and share experiences, offer suggestions, and feedback in a nonjudgmental free zone. This is refreshing since there is no judgement and the faculty who attend really have their colleagues' and students' interests at heart. Carly (NP)

\section{Summary}

The themes reflect the areas of focus developers of university provided PD must take into consideration when creating professional development curricula, workshops, and seminars with the faculty member in mind. The participants felt a professional and personal responsibility to share their perspectives and observations of what is needed to cultivate a culture where online adjunct faculty's voices are heard and integrated in the development and dissemination of meaningful and relevant PD. From the adjunct faculty's perspective, meaningful and relevant PD content, especially during COVID-19, needed to have a focus on the mental health and wellness of both faculty and students. Additionally, the participants noted the importance of focusing on issues that are related to COVID-19 such as university accepted practices to support students, modifications to assignments and flexibility of due dates, and working with students who traditionally took in-person classes and transitioned into distance learning due to COVID in order to maintain their standing within the university program or financial aid assistance. Each participant noted the importance of developing a collegial relationship with educators to share knowledge with open lines of communication. Participants described their experiences of sharing knowledge pertaining to ongoing PD for higher education institutions to gain an awareness of the needs of online adjunct faculty. They commented on how current, timely, and pertinent PD opportunities, specifically in times of uncertainty brought about by unforeseen events such as the COVID-19 pandemic, can be integrated and applied to further support faculty personal development, mental health, wellbeing, and academic growth.

\section{Discussion}

With the current educational climate influenced by the global pandemic, our intention in this study was to share the experiences of online adjunct faculty who are knowledgeable of PD opportunities throughout their tenures within higher education prior to and during the COVID-19 pandemic. Accountability, pressures, and demands that are placed on higher education institutions have shown that, in some cases, the level of success 
in supporting faculty, especially when unpredictable demands arise, varies greatly depending on the mission and vision of the institution (Roy \& Covelli, 2020; Ulmer, 2020; Vlachopoulos, 2020).

Additionally, many universities struggle to provide support services for online adjunct faculty, leaving faculty to their own devices to adapt to each situation that is presented (Roy \& Covelli, 2020). Both not-for-profit and for-profit online adjunct faculty have approached PD sessions with a readiness to learn, a willingness to collaborate with other faculty, and derive some key takeaways that they can apply in the classroom. Based on the findings of this study, it is clear that online adjunct faculty from universities and colleges that are not-forprofit tend to value professional growth opportunities and services greater than faculty from for-profit universities.

There are instances where PD can address the continued need for personal and professional academic growth, especially in times of sudden change (Piazza \& Rizzari, 2020; Roy \& Covelli, 2020). Thus, online adjunct faculty can hone new skills used to support student learning that can be applied to the classroom. Piazza and Rizzari (2020) affirmed the importance of improving the quality of university teaching. This ties in with the theme Faculty Needs to Support Students which emerged from our study. While PD opportunities exist to support "the art and science of helping adults learn" (Loeng, 2018, p. 4), in some instances PD needs to have the flexibility to be modified or updated to address current issues that arise in times of crisis.

Participants in this study mentioned, on several occasions, the need for current and relevant content, points encapsulated in the themes of Importance of Professional Development Content and Relevance of Professional Development Content. This study was conducted during the COVID-19 pandemic which created a "new world" for online faculty and the students they serve. The literature review showed a desired outcome of the PD process was for learning with content for faculty to authentically learn tasks based on real-world activities (Doherty, 2011; Gast et al., 2017; Gutterman \& Mitchell, 2016; Stewart, 2014), which is in keeping with our research findings.It was mentioned earlier that faculty will pursue PD if the content is equitable, meaningful, includes praxis and reflection, and will increase their level of job satisfaction throughout their career (MacPhail et al., 2019; Stewart, 2014). This again agrees with the themes of Importance of Professional Development Content and Relevance of Professional Development Content derived from this study.

Faculty also noted the importance of embracing the learning process, which necessitates additional time to comprehend the realities of what is happening at the university level due to COVID-19 (Polikoff et al., 2020). Therefore, it is entirely reasonable that online adjunct faculty could rely on modifications of content presented in PD offerings to maneuver the changes needed to continue to be effective in the classroom and to support students when the need arises.The other themes that emerged from our research-namely Communication and Collegiality; Synchronous Engagement; and Self-Actualization did not explicitly emerge in the previous studies reviewed. These findings add to the literature about faculty professional development. As mentioned in the literature review, while the correlation between the PD of faculty and the advancement of student learning is evident, PD has not been given continuous and systematic awareness by universities to support their online adjunct faculty (Penuel \& Gallagher, 2017). This makes the current study relevant and necessary to add to the continuity mentioned and to increase the body of knowledge on the PD of faculty.

\section{Significance}

Online adjunct faculty are significant change agents within their universities. The faculty's perceptions on how universities value their online adjunct faculty as members of the university community may play a crucial role in determining the importance placed on PD practices. Relevant insights into online adjunct faculty's PD experiences and their perspectives about needed enhancements to PD are at the heart of the current study. The contributions and findings from this study could benefit course enhancement and curriculum development of university-based PD programs to support the teaching of online adjunct faculty, which are not 
location or time specific, and may be beneficial given the need for social distancing and other ramifications necessitated by the current COVID-19 pandemic. Therefore, developing PD programs specifically to address the unique needs and experiences of online adjunct faculty that focus on the relevance of content, synchronous engagement, and how to specifically support students during times of crises, could be beneficial to the university and ultimately the students served (Setswe et al., 2019; Vlachopoulos, 2020). These PD programs could entail adding specific reading content and tailored collaborative synchronous discussion activities to address the expressed concerns raised by online adjunct faculty to the university. The inclusion of such content and collaborative activities would serve as a model for how online adjunct faculty can approach their own course instruction. Additionally, such programs could help to meet online adjunct faculty's needs of self-esteem and self-actualization, which may lead to increased job satisfaction and performance. A deeper understanding of the impact of relevant PD based on online adjunct faculty needs, especially due to the onset and continuous impact of the COVID-19 pandemic, should be researched further.

\section{Limitations of the Study}

Several limitations need to be addressed. First, the number of participants and population was derived from a single professional international educational organization, AECT. Although the initial invitation to participate in the study was sent to approximately 2000 members of AECT, a limited number of 40 participants replied to the solicitation with 18 agreeing to be interviewed. Although participants invited to take part in the study were from a single educational professional organization, future studies could include participants from multiple professional organizations, practitioners in the field, and higher education institutions. To increase the number of participants and broaden the applicability of any future findings, professional snowball sampling as a method of selection of participants could be employed. Future research is needed that directly examines satisfaction among veteran online adjunct faculty based on faculty driven professional development initiatives offered by their respective institutions of higher education. Additional research studies may focus on the relationship of differing approaches to professional development and online adjunct faculty success in the classroom.

\section{Implications for Theory and Practice}

While online adjunct faculty are accustomed to the online teaching platform, they are confronted with new challenges emanating from the COVID-19 pandemic. For example, online adjunct faculty now had to assist a higher number of students in understanding and navigating the nuances of a different learning system as they had shifted to an online delivery platform and provide support to help students cope with the stressors and personal crisis created by the pandemic. This study is particularly timely given the current increase of university courses offered and taught by online adjunct faculty due to the onset of the global pandemic. Higher education institutions need to be able to readily adapt and change in times of crises to support faculty (Roy \& Covelli, 2020; Ulmer, 2020). From the perspective of online adjunct faculty, this is an opportune time for universities to work collectively with their online adjunct faculty to truly listen to their voices to develop stealthy, current, and relevant PD.

Future research should aim to identify specific measures universities can take to listen, cultivate, develop, and implement PD opportunities for online adjunct faculty that take into consideration the specific observations and unique virtual teaching experiences faced by faculty and students. Other studies based on this initial work may nurture and inform successful implementation of PD programs at online universities to support and retain online adjunct faculty. Other research questions to consider may include: When do online adjunct faculty know their university values their contributions? How does a university ensure online adjunct faculty voices are heard in developing quality online courses? What types of avenues will universities offer to online 
adjunct faculty to increase faculty engagement in university governance? From an online adjunct faculty perspective, what are the types of PD needed to address the challenges of distance learning amid the COVID19 pandemic? What do online adjunct faculty think is necessary and important to overcome these problems? Better understanding of these issues could provide useful guidance on specific ways to target increased engagement of online adjunct faculty in matters of university governance to support online adjunct faculty job satisfaction, retention, and engagement.

\section{Conclusions}

This study reminds us that there are numerous variables, including unforeseen crises such as the COVID-19 pandemic, that need to be considered when developing, implementing, and presenting PD for online adjunct faculty professional and personal growth. Because faculty want to be listened to and heard, the PD

development and implementation process needs to be interactive with buy-in and support within all levels of higher learning institutions to support online adjunct faculty, regardless of whether the university is for-profit or not-for-profit. Since there is not a one-size-fits-all university, the same holds true for PD that is offered to online adjunct faculty. Professional growth opportunities for online adjunct faculty should be a meaningful interaction and exchange of ideas to further support faculty while upholding the mission and vision of each respective institution. 


\section{References}

Abela, J. (2009). Adult learning theories and medical education: A review. Malta Medical Journal, 21(1), 11-18. https://www.researchgate.net/publication/281060971_Adult_learning_theories_and_medical_educat ion_A_review

Almazova, N., Krylova, E., Rubtsova, A., \& Odinokaya, M. (2020). Challenges and Opportunities for Russian Higher Education amid COVID-19: Teachers' Perspective. Education. Sciences 1O(12), 368. https://doi.org/10.3390/educsci10120368

Asio, J. M., \& Jimenez, E. (2020). Professional development, organizational climate, supervisory rapport, and overall satisfaction of employees: An attitudinal study. International Journal of Scientific Research in Multidisciplinary Studies, 6(4), 34-40, https://papers.ssrn.com/sol3/papers.cfm?abstract_id=3624812

Baker, V. L. (2020). Now's not the time to cut faculty development funds. Inside Higher Ed. https://www.insidehighered.com/advice/2020/o9/o8/four-ways-investing-professionaldevelopment-now-can-benefit-both-faculty-and

Baran, E., \& Correia, A. P. (2014). A professional development framework for online teaching. Tech Trends, 58, 95-101 (2014). https://doi.org/10.1007/s11528-014-0791-o

Bartle, M. S. (2008). Andragogy. Research Starters: Education (Online Edition). http://www.academicpub.com/map/items/171530.html

Boddy, C. (2016). Sample size for qualitative research. Qualitative Market Research, 19(4), 426-432. https://doi.org/10.1108/QMR-06-2016-0053

Buus, N., \& Perron, A. (2020). The quality of quality criteria: Replicating the development of the Consolidated Criteria for Reporting Qualitative Research (COREQ). International Journal of Nursing Studies, 102, 103452. https://doi.org/10.1016/j.ijnurstu.2019.103452

Cheatham, J. P. (2020, October 14). Becoming a school leader during COVID-19. https://www.gse.harvard.edu/news/uk/20/10/becoming-school-leader-during-covid-19

Curwood, J. S. (2011). Teachers as learners: What makes technology-focused professional development effective? English in Australia (o155-2147), 46(3), 68-75.

https://www.researchgate.net/publication/272819683_Teachers_as_Learners_What_makes_techn ology-focused_professional_development_effective

Dailey-Hebert, A., Norris, V. R., Mandernach, B. J., \& Donnelli-Sallee, E. (2014). Expectations, motivations, and barriers to professional development: Perspectives from adjunct instructors teaching online. The Journal of Faculty Development, 28(1), 67-82.

Darling-Hammond, L., Hyler, M. E., \& Gardner, M. (2017). Effective teacher professional development. Learning Policy Institute. https://static1.squarespace.com/static/56b9ocb101dbae64ff707585/t/5ade348e70a6ad624d417339/ 1524511888739/NO_LIF 1.PDF

Dede, C. (2004). Distributed-learning communities as a model for educating teachers. Paper presented at the Society for Information Technology \& Teacher Education International Conference 2004, Atlanta, GA, USA.

Diep, A. N., Zhu, C., Cocquyt, C., De Greef, M., Vo, M. H., \& Vanwing, T. (2019). Adult learners' needs in online and blended learning. Australian Journal of Adult Learning, 59(2), 223-253. https://files.eric.ed.gov/fulltext/EJ1235812.pdf 
Doherty, I. (2011). Evaluation the impact of professional development on teaching practice: Research findings and future research directions. US-China Education Review, A(5), 703-714.

Earp, J. (2020, August 12). Changing school leadership during COVID-19. https://www.teachermagazine.com/au_en/articles/changing-school-leadership-during-covid19?utm_source=Twitter\&utm_medium =socialmedia\&utm_content=social

Easterly, R. G. T., \& Myers, B. E. (2019). Professional development engagement and career satisfaction of agriscience teachers. Journal of Agricultural Education, 6o(2), 69-84. https://doi.org/10.5032/jae.2019.02069

Felber, S. (2020). Adjunct faculty participation in the centralized design of online courses. Online Journal of Distance Learning Administration, 23(1). https://www.westga.edu/ distance/ojdla/spring231/felber231.html

Frass, L. R., Rucker, R. D., \& Washington, G. (2017). An overview of how four institutions prepare faculty to teach online. Journal of Online Higher Education, 1(1), 1-7.

Frerichs, S. W., Fenton, M. S. P., \& Wingert, K. (2018). A model for out-of-school educator professional learning. Adult Learning, 29(3), 115-122. https://doi.org/10.1177/1045159518773908

Gast, I., Schildkamp, K., \& van der Veen, J. T. (2017). Team-based professional development interventions in higher education: A systematic review. Review of Educational Research, 87(4), 736-767. https://doi.org/10.3102/0034654317704306

Guskey, T. R. (2003). What makes professional development effective? The Phi Delta Kappan, 84(10), 748. https://doi.org/10.1177/003172170308401007

Gutterman, T. C., \& Mitchell, N. (2016). The role of leadership and culture in creating meaningful awareness: A mixed method case study. Innovations in Higher Education, 41, 43-57. https://doi.org/10.1007/s10755-015-9330-y

Herrington, J., \& Oliver, R. (2000). An instructional design framework for authentic learning environments. Educational Technology Research and Development, 48(3), 23-48.

Hetland, L., Winner, E., Veeman, S., \& Sheridan, K. M. (2013). Studio thinking 2: The real benefits of visual arts education (2nd ed.). Teachers College Press.

Hussain, I. (2013). A study of learners' reflection on andragogical skills of distance education tutors. International Journal of Instruction, 6(1), 123-138.

Hwang, S. (2021). The mediating effects of self-efficacy and classroom stress on professional development and student-centered instruction. International Journal of Instruction, 14(1), 1-16. https://doi.org/10.29333/iji.2021.1411a

James, S. G., \& Binder, D. A. (2012). The care and feeding of part-time faculty: A model to retain community college adjuncts. National Forum of Educational Administration and Supervision Journal, 28(3), 2011-2012.

Johnston, E., Rasmusson, X., Foyil, B., \& Shopland, P. (2017). Witnesses to transformation: Family member experiences providing individualized music to their relatives with dementia. Cogent Education, 4(1), 1362888. https://doi.org/10.1080/2331186X.2017.1362888

Kim, J. H. (2016). Understanding narrative inquiry: The crafting and analysis of stories as research. SAGE.

Knowles, M. S. (1980). Modern practice of adult education: Andragogy vs. Pedagogy. Follett. (Original work published 1970). 
Kuder Coach (2018, August 27). Effective outcomes from professional development. https://www.kuder.com/blog/career-counseling-coaching/effective-outcomes-from-professionaldevelopment/

Lederman, D. (2019, December 17). The biggest movers. Inside Higher Ed. https://www.insidehighered.com/digital-learning/article/2019/12/17/colleges-and-universitiesmost-online-students-2018

Loeng, S. (2018). Various ways of understanding the concept of andragogy. Cogent Education, 5(1), 1. https://doi.org/10.1080/2331186X.2018.1496643

MacPhail, A., Ulvik, M., Guberman, A., Czerniawski, G., Oolbekkink-Marchand, H., \& Bain, Y. (2019). The professional development of higher education-based teacher educators: Needs and realities. Professional Development in Education, 45(5), 848-861. https://doi.org/10.1080/19415257.2018.1529610

Maslow, A. H. (1943). A theory of human motivation. Psychological Review, 50 (4), 370. http://psychclassics.yorku.ca/Maslow/motivation.htm

Merriam, S. B. (2001). Andragogy and Self-Directed Learning: Pillars of Adult Learning Theory. New Directions for Adult \& Continuing Education, 2001(89), 3. https://doi.org/10.1002/ace.3

Mohr, S., \& Shelton, K. (2017). Best practices framework for online faculty professional development: A Delphi study. Online Learning, 21(4), 123-140. https://doi.org/10.24059/olj.v21i4.1273

Namaganda, A. (2020). Continuing professional development as transformational learning: A case study. The Journal of Academic Librarianship, 46(3). https://doi.org/10.1016/j.acalib.2020.102152

Penuel, W. R., \& Gallagher, D. J. (2017). Creating research-practice partnerships in education. Harvard Education Press.

Piazza, R., \& Rizzari, S. (2020). The professional development of faculty and teaching quality: The peer review as a participatory training method . Form@re-Open Journal Per La Formazione in Rete, 20(1), 6277. https://doi.org/10.13128/form-8271

Polikoff, M., Silver, D., \& Korn, S. (2020, August 4). What's the likely impact of COVID-19 on higher ed? Inside Higher Ed. https://www.insidehighered.com/views/2020/o8/04/analysis-data-nationalsurvey-impact-pandemic-higher-ed-opinion

Queens University of Charlotte. (2021). The importance of professional development for educators. https://online.queens.edu/resources/article/professional-development-for-educators/

Rienties, B., Brouwer, N., \& Lygo-Baker, S. (2013). The effects of online professional development on higher education teachers' beliefs and intentions towards learning facilitation and technology. Teaching and Teacher Education, 29, 122-131. http://dx.doi.org/doi:10.1016/j.tate.2012.09.002

Riessman, C. K., \& Speedy, J. (2018). Narrative inquiry in the psychotherapy professions. In N. K. Denzin \& Y. S. Lincoln (Eds.), The SAGE handbook of qualitative research (5th ed.), (pp. 427-456). SAGE

Roy, S., \& Covelli, B. (2020). COVID-19 induced transition from classroom to online mid semester: Case study on faculty and students' preferences and opinions. Higher Learning Research Communications, 11, 10-32. https://doi.org/10.18870/hlrc.v11io.1197

Saldaña, J. (2015). The coding manual for qualitative researchers (3rd ed.). SAGE.

Saldaña, J., \& Omasta, M. (2022).Qualitative research: Analyzing life (2nd ed.). SAGE.

Salmi, J. (2020). COVID's lessons for global higher education: Coping with the present while building a more equitable future. https://www.luminafoundation.org/wp-content/uploads/2020/11/covids-lessonsfor-global-higher-education.pdf 
Schaffhauser, D. (2015). Survey: Not enough training, instructional support for online adjunct faculty . https://campustechnology.com/articles/2015/11/16/survey-not-enough-training-instructionalsupport-for-online-adjunct-faculty.aspx

Schulte, M. (2018). Adult learning degree and career pathways: Allusions to Maslow's hierarchy of needs. Journal of Continuing Higher Education, 66(1), 62-64.

Setswe, G., Madiope, M., \& Makoe, M. (2019). The Use of Mobile Learning Technologies for the Professional Development of Academics at a University of Technology. Proceedings of the European Conference on Research Methods for Business \& Management Studies, 378-385. https://doi.org/10.34190/RM.19.098

Sheridan, K. (2009). Studio thinking in early childhood. In M. Narey (Ed.). Making meaning arts-based early childhood education constructing multimodal perspectives of language, literacy, and learning through arts-based early childhood education. (pp. 71-90). Springer.

Shilpa Joshi, R. V. (2017). The significance of andragogy in present day higher education "Creating and implementing with a learning experience in a $\mathrm{n}$ atmosphere of competency, commitment \& credibility." International Journal of Innovative Science and Research Technology, 2 (5), 7. https://ijisrt.com/wp-content/uploads/2017/05/The-Significance-of-Andragogy-in-present-dayhigher-Education.pdf

Showers, B., Joyce, B., \& Bennett, B. (1987). Synthesis of research on staff development: A framework for future study and a state-of-the-art analysis. Educational Leadership, 45(3), 77. http://www.ascd.org/ASCD/pdf/journals/ed_lead/el_198711_showers.pdf

Steele, P., Burleigh, C., Bailey, L., \& Kroposki, M. (2020). Studio thinking framework in higher education: Exploring options for shaping immersive experiences across virtual reality/augmented reality curricula. Journal of Educational Technology Systems, 48(3), 416-439. https://doi.org/10.1177/0047239519884897

Stewart, C. (2014). Transforming professional development to professional learning. Journal of Adult Education, 43(1), 28-33.

Straumsheim, C. (2015). Supporting online adjuncts. Inside Higher Ed. https://www.insidehighered.com/news/2015/11/12/study-explores-hiring-and-managing-practicesonline-adjunct-faculty-members

Tyers, D., \& Sillito, J. (2018). Locating continuing professional development within a proposed complex dynamic systems model for today's English language teaching profession. TESL Canada Journal, 35(2), 179-193.

Ulmer, W. (2020). Leader-to-leader: Reflexive leadership in the midst of Covid-19 and social unrest. Journal of Social Change, 13, 1-6. https://doi.org/10.5590/JOSC.2020.13.1.02

van Dijk, E. E., van Tartwijk, J., van der Schaaf, M. F., \& Kluijtmans, M. (2020). What makes an expert university teacher? A systematic review and synthesis of frameworks for teacher expertise in higher education. Educational Research Review, 31, 100365. https://doi.org/10.1016/j.edurev.2020.100365.

Vlachopoulos, D. (2020). COVID-19: Threat or opportunity for online education? Higher Learning Research Communication, 1O(1), 16-19. https://doi.org/10.18870/hlrc.v10i1.1179

Williams, T., Layne, M., \& Ice, P. (2014). Online faculty perceptions on effective faculty mentoring: A qualitative study. Online Journal of Distance Learning Administration, 17(2), 1-19. http://www.westga.edu/ distance/ojdla/summer172/Williams_Layne_Ice172.html

Yin, R. K. (2018). Case study research and applications: Design and methods (6th ed.). SAGE.

Ziegler, M., Paulus, T., \& Woodside, M. (2006). Creating a climate of engagement in a blended learning environment. Journal of Interactive Learning Research, 17(3), 295-318. 


\section{Appendix}

\section{Interview Questions}

\section{Demographic Questions/Ice Breakers}

- Could you tell me the area that best describes your age: 30-40, 41-50, 51-60, older?

- Do you work for a non-profit or for-profit online university?

- What is your primary area of teaching, department, or college?

- How long have you been participating in PD experiences at your university?

\section{Interview Questions}

When responding to any of the following questions, also consider the impact COVID-19 has had on opportunities for PD, personal and professional academic growth, and supporting students during these unprecedented times.

\section{Types of PD Experiences}

- What type of PD have you been a participant? Webinars, workshops, or training, or other.

- How often are the PD events held?

- What are some of the content or topics that are covered in the PD? Has the content or those topics changed due to COVID?

- Are the PD events based on university updates such as changes in university policy? Or something else?

- How often are refresher PD events held? Are those mandatory or optional? Does the university compensate you for attending? Are these events synchronous or asynchronous?

- What are your expectations when you experience PD? Has these expectations changed because of COVID? Suggested Prompt: Tell me more about that.

- What are your top concerns? Suggested Prompt: Tell me more about that.

- Can you tell me about a time where you were participating in PD and you were having a positive experience?

- Can you tell me about a time where you were participating in PD and you were having a negative experience? How would you have guided the content to a more positive experience?

- Have you ever encountered a conflict when given direction in PD? Did the training, workshop, or webinar state something that was different from the direction you may have been given by a supervisor or who you directly report to?

- What changes would you make in the PD in order to foster a more positive outcome? Tell me about what components of PD would encourage a positive experience.

- What components of PD do you consider promoted a negative experience?

- During any of your PD experiences, were there any surprises?

\section{Surveys and Opportunity to Provide Feedback}

- Do you have the opportunity to complete a survey about the PD experience? Does the survey have an open-ended question?

- What comments, suggestions, or feedback would you share with those who facilitated the PD?

- What comments, suggestions, or feedback would you share with faculty to encourage their participation in PD? 


\section{Personal Academic Growth}

- How has PD supported your personal and professional academic growth as a faculty member for your university? Has this changed because of COVID?

- What type of PD opportunities would you like to see that would support your personal growth? Also consider the impact of COVID.

- Do you ever attend PD opportunities that are not offered by your university, sponsored by a professional organization, to further your personal and professional academic growth? If so, what are these and how often? Has this changed due to COVID? If so, how?

\section{PD and Your University}

- How do PD opportunities make you feel about your university? Suggested prompt: Consider prior to COVID and now.

- Would the support that you have received in PD encourage you to ask other educators who are not faculty at your institution to apply for a position within your university?

\section{Onboarding}

- If you can remember your onboarding experience with your university, what was that experience like?

- If you have changed positions within the university, did you receive additional onboarding-type training for the new position?

- For example, you have been asked to teach a master's seminar course where in the past you had been teaching undergraduate content classes. Or at the doctoral level you have taught content classes, now you are a methodologist that works with a specific group of doctoral students throughout their doctoral journey.

- If you have not received additional training support for a new position, do you believe the training or having a mentor would have been helpful? Why or why not?

\section{Closing}

- Do you have any questions or anything that you would like to add to our conversation about PD?

- Thank you for participating in the study.

The Higher Learning Research Communications (HLRC), is a peer-reviewed, online, interdisciplinary journal indexed in Scopus, ERIC, JGATE and Directory of Open Access Journals (DOAJ). It is an open access journal with an international focus published by Walden University, USA. Its aim is to disseminate both high quality research and teaching best practices in tertiary education across cultures and disciplines. HLRC connects the ways research and best practice contribute to the public good and impact the communities that educators serve. $H L R C$ articles include peer-reviewed research reports, research briefs, comprehensive literature reviews, and books reviews. 